
\title{
$\begin{array}{ll}\text { Research Square } & \text { Preprints are preliminary reports that have not undergone peer review. } \\ \text { They should not be considered conclusive, used to inform clinical practice, } & \text { or referenced by the media as validated information. }\end{array}$
}

\section{A Randomized Clinical Trial on Combination Use of Sirolimus and Tacrolimus in Renal Transplant: A De novo Immunosuppression Approach}

\section{Farzaneh Hematian}

Shaheed Beheshti University of Medical Sciences

Nooshin Dalili

Shahid Beheshti University of Medical Sciences School of Medicine

\section{Pedram Ahmadpoor}

Shahid Beheshti University of Medical Sciences School of Medicine

\section{Omid Moradi}

Shahid Beheshti University of Medical Sciences School of Pharmacy

\section{Fatemeh Pour-reza-gholi}

Shahid Beheshti University of Medical Sciences School of Medicine

Shiva Samadian

Shahid Beheshti University of Medical Sciences School of Medicine

\section{Fariba Samadian}

Shahid Beheshti University of Medical Sciences School of Medicine

\section{Mohsen Nafar}

Shahid Beheshti University of Medical Sciences School of Medicine

\section{Ahmad Firoozan}

Shahid Beheshti University of Medical Sciences School of Medicine

Shadi Ziaie ( $\sim$ shadi_z73@yahoo.com )

Shahid Beheshti University of Medical Sciences School of Pharmacy

\section{Research article}

Keywords: Kidney transplantation, Immunosuppressive Agents, Mammalian target of rapamycin, Calcineurin Inhibitors, Graft Rejection, Sirolimus, Tacrolimus

Posted Date: January 7th, 2020

DOI: https://doi.org/10.21203/rs.2.20145/v1

License: (c) (1) This work is licensed under a Creative Commons Attribution 4.0 International License. Read Full License 


\section{Abstract}

Background: With the introduction of new immunosuppressive agents like Sirolimus (SRL), we could increase long term allograft survival and decrease the use of other agents like calcineurin inhibitors. SRL in combination with other immunosuppressive medications like calcineurin inhibitors can lead to increase graft function and produce better long-term outcomes.

Methods : We enrolled 40 kidney transplantation recipients in trial and followed them up for a duration of 6 months in Shahid Labbafinejad Medical Center. These patients were assigned to receive Tacrolimus (TAC) in combination with Mycophenolic acid or SRL, along with glucocorticoids. All kidney transplant recipients were followed up for serum creatinine and glomerular filtration rate and also complications during therapy.

Results : There were no significant differences between the two treated groups regarding serum creatinine level ( $p$-values $=0.075)$. However, glomerular filtration rate was significantly increased in SRL group than the other one $(p$-values $=0.023)$. There was no difference between the number of biopsies performed in the two treated groups. In biopsies that were done, in TAC/Mycophenolic acid group, acute antibody mediated rejection in four patients and in SRL/TAC group, acute cellular rejection in two patients were reported. Total cholesterol level was significantly increased in patients who received SRL ( $p$-values = 0.002). Other side effects were not significantly different in two arms.

Conclusions : Our study demonstrated that SRL in the immunosuppressive regimen of kidney transplant recipients in de novo approach lead to better renal function. The long-term outcomes of de novo SRL utilization in kidney allograft recipients should further be assessed. Trial registration: The trial was retrospectively registered in the Iranian Registry on Clinical Trials ( www.irct.ir , registration code: IRCT20160412027346N6), by the date of 04/30/2019. ( https://www.irct.ir/trial/22416) Key words : Kidney transplantation, Immunosuppressive Agents, Mammalian target of rapamycin, Calcineurin Inhibitors, Graft Rejection, Sirolimus, Tacrolimus.

\section{Background}

Kidney transplantation is the optimal treatment option of patients with end stage renal disease (ESRD) [1]. With introduction of calcineurin inhibitors (CNIs) such as cyclosporine in 1980s, as main Immunosuppressive medication to be used in patients who were undergone kidney transplantation, recipients experienced increased in short term survival and decrease in number of acute rejection episode [2]. Although, CNls have reduced incidence of acute rejection and increased short-term survival of graft, long-term survival with the use of these agents is limited [3]. The failure of these agents in long term survival, is due to delayed nephrotoxicity that causes chronic allograft dysfunction [4-7]. Most centers currently use CNIs as maintenance immunosuppression therapy. In this pharmacologic categoric, cyclosporine was used most commonly. In spite of acute and chronic nephrotoxicity, other side effects such as hypertension, metabolic adverse effects, risk of malignancy and opportunistic infections are 
common in patients who use CNIs [8]. Dose adjustment and therapeutic drug monitoring for reducing nephrotoxicity and over immunosuppression as well as prevention of immunological allograft failure are some burdens for CNI use. With the introduction of newer medications such as Sirolimus (SRL), use of CNIs as an immunosuppressive is reducing [9-12]. SRL has many beneficial effects like increased long term survival, improvement of renal function, better quality of life and lower risk of malignancy [13-17]. Combination of SRL and CNIs provides effective immunosuppression by strong synergistic pharmacologic effect and permits dose reduction of CNIs $[18,19]$. It is notable that the use of SRL without CNIs did not improved post-transplant outcome in terms of acute rejection, graft function and survival in previous studies [20-22]. The early use of SRL is associated with a series complication such as impaired wound healing, hyperlipidemia, new onset diabetes after transplantation (NODAT) [23, 24]. Many of this complication depend on the initiation time for SRL consumption after transplantation and dose of the medication. Therefore, therapeutic drug monitoring of SRL, appropriate time for initiation and avoiding the use of SRL in high risk recipients, can decrease the risk of these side effects and graft loss [24]. Efficacious immunosuppression regimen with the highest long-term survival is not known yet. One of the options is to use sirolimus by de novo approach (in first day after transplantation) combined with Tacrolimus (TAC). Therefore, the purpose of this study was to examine de novo use of SRL and TAC combination versus mostly used immunosuppressive regimen, tacrolimus and mycophenolic acid.

\section{Methods}

\section{Study design and patient selection}

In this prospective randomized clinical trials, 43 renal transplant recipients were included to be followed for a duration of 6 months. We enrolled kidney transplant recipients between years 2016 and 2017 in Shahid Labbafinejad Medical center. Study was done in accordance with the declaration of Helsinki. The trial was registered in the Iranian Registry on Clinical Trials (www.irct.ir, registration code: IRCT20160412027346N6). It was approved by the ethics committee of Shahid Labbafinejad medical center, Tehran, Iran. Written informed consents were obtained from all patients before enrollment. Patients were randomly selected and divided into two groups of test and control. Randomization was computer generated. Block randomization method has be used and each block was of 10 patients. The inclusion and exclusion criteria were as followed. All patients who received kidney transplant from cadaver or unrelated living donor (age of cadaveric donor $<50$ years) that were negative for panel reactive antibody (cytotoxicity), pre-transplantation Anti-human leukocyte antigens (HLA), were recruited. All patient were 18 to 65 years of age and had body mass index (BMI) less than $30 \mathrm{~kg} / \mathrm{m}^{2}$. Patients who received kidney transplant previously were not included. Increase in serum creatinine higher than $3 \mathrm{mg} / \mathrm{dl}$ in day 3 post-transplantation as an indicator of slow graft Function (SGF) and dialysis in first week as an indicator of delayed graft function (DGF) were defined as exclusion criteria.

\section{Immunosuppression protocols}


After transplantation, the patients were randomly received one of the immunosuppressive regimens as followed. Combination of TAC (Prograf $®$; AstraZeneca, Cambridge, United Kingdom), SRL (Rapamune ${ }^{\circledR}$; Pfizer, New York City, New York, United States) and Corticosteroids for test group and TAC, Mycophenolate sodium (Myfortic $® ;$; Novartis, Basel, Switzerland) and Corticosteroids in control group. All patients received Antithymocyte Globulin (ATG) for immunosuppression induction. Immunosuppressive medications were administered with the following dosages. ATG $3 \mathrm{mg} / \mathrm{kg}$ divided in 3 to 4 doses daily. Methylprednisolone $250 \mathrm{mg}$ daily for 2 days, followed by prednisolone $1 \mathrm{mg} / \mathrm{kg}$ (maximum of $60 \mathrm{mg}$ ) for 3 days afterward, then it was tapered by $5 \mathrm{mg}$ daily to reach the dose of $15 \mathrm{mg}$ on day $14,10 \mathrm{mg}$ daily on day 30 and finally $5 \mathrm{mg}$ daily on day 60 and thereafter. Patients received same doses of ATG and Steroid in 2 group. In test group, SRL, $2 \mathrm{mg}$ as a loading dose followed by doses to reach the trough levels of 3$5 \mathrm{ng} / \mathrm{mL}$ as maintenance regimen in combination with TAC, $0.08 \mathrm{mg} / \mathrm{kg} /$ day for trough levels of 6$7 \mathrm{ng} / \mathrm{mL}$ in first 6 months after transplantation were administered. In control group, TAC, $0.1 \mathrm{mg} / \mathrm{kg} / \mathrm{day}$ to reach the trough level of $8-10 \mathrm{ng} / \mathrm{ml}$; Myfortic ${ }^{\circledR}, 1080 \mathrm{mg}$ daily for 7 first day followed by $720 \mathrm{mg}$ as maintenance regimen in first 6 months after transplant.

\section{Data collection}

Collecting required demographic, clinical, preclinical data were performed under supervision of a clinical pharmacist. The recorded data were included age, sex, BMI, source of allograft tissue (living/cadaveric), reason for chronic kidney disease, underlying diseases and comorbidities, PRA, anti-HLA and immunosuppressant medications. Glomerular filtration rate (GFR) estimated by The Modification of Diet in Renal Disease Study (MDRD) equation [25], number of biopsy proven acute rejection, protocol biopsy of 4th month to evaluated the frequency of borderline changes, subclinical acute cellular rejection and subclinical antibody mediated rejection by BANFF II classification, frequency of NODAT, Hypertension, Dyslipidemia, Cytomegalovirus (CMV) viremia (>2000 copy/ml) and CMV disease (Fever, leukopenia or organ involvement + CMV DNA > 2000 copies $/ \mathrm{ml}$ ), BK viremia (> $10000 \mathrm{copy} / \mathrm{ml}$ blood) and BK virus associated nephropathy, Hospitalization and graft loss were documented.

\section{Statistical analysis}

All statistical analyses were performed by the Statistical Package for the Social Sciences (SPSS) version 20.0 software. Mean and standard deviation were used to expressed continuous variables and numbers and percentage for categorical variables. Paired t-test were used for comparison of the quantitative data and the chi-square test for qualitative ones. $p$-values less than 0.05 were considered to be statistically significant.

\section{Results}

Entry and participant flow through the study are shown in figure 1. A total of 45 patients were recruited. Two patients were excluded because of severe Acute Tubular Necrosis (ATN) and then nephrectomy and dialysis need after one-week post transplantation. After 6 months within follow-up, 18 and 22 patients were remained in the test group and control group, respectively. The baseline characteristics of patients 
were expressed in Table 1. Categorical variables were homogenous between two groups and there were no statistical differences between two groups in comparing other variables. The mean of age was $33.7 \pm 9.9,35.5 \pm 12.2$ years for test and control group, respectively. There were no significant differences between two treated groups regarding serum creatinine level for 6 months after transplantation ( $p$-values $=0.075)$. However, patients who received SRL included immunosuppressant medication regimen, experienced more rapid increase in GFR and this difference was statistically significant ( $p$-values $=0.023$ ) (Figures 2). There were significant differences regarding their total cholesterol level ( $p$-values $=0.002$ ). Total cholesterol and triglyceride level in SRL group were increased in comparison to control group. But there were no significant differences between two treated groups regarding triglyceride level ( $p$-values $=$ 0.391) (Figure 3, Table 2). Mean arterial pressure (MAP) and fasting plasma glucose (FPG) were not significantly different. (Figure 3 and Table 2). On patient in control group was infected by CMV at the end of the third month, which was treated with valgancyclovir. Similarly, BK viremia was reported only in one patient in control group. There were no significant differences between the two treated groups regarding their number of biopsies on indications ( $p$-values $=0.999$ ). Protocol of biopsy was done on 16 patients in two treated groups, Nine and seven patients from control and test group, respectively. There were no significant differences between the two groups regarding number of protocols of biopsy ( $p$-values $=$ 0.633). From nine patients in control group, five recipients had been reported with normal pathology, in three cases acute cellular rejection were reported and one patient had been shown Acute AntibodyMediated Rejection (ABMR). In seven patients of test group, five patients had been reported with normal pathology and in two patients, simple ATN and recurrent membranous glomerulonephritis (MGN) were reported. There were no significant differences between the two groups regarding the duration of hospitalization and number of re-hospitalizations after transplantation ( $p$-values $=0.616)$ (Table 3$)$. Readmission of patients in control group were reported as 11 times. the most frequent reason for hospitalization after transplantation in this group wat urinary tract infection with E.coli microorganism. Other seven recipients were hospitalized after receiving the allograft because of leukopenia $(\mathrm{WBC}<1000)$ in two patients, pancytopenia, CMV infection, renal artery stenosis in three patients and two recipients were diagnosed by acute rejection. Similarly, the most frequent cause for Re-hospitalization in test group were reported as, urinary tract infection due to E.coli microorganism. One patient in this group hospitalized after transplantation for treating leukopenia $(\mathrm{WBC}<1000)$ and one patient with pulmonary emboli. In test group three patients were diagnosed with acute rejection.

\section{Discussion}

Effectiveness of combine use of SRL and TAC in prevention of acute rejection, preserve renal function and safety is not well established in contrast to conventional immunosuppressive regimen of Mycophenolic acid and TAC. In addition, it is expected that use of SRL could facilitate TAC dose reduction while maintaining immunosuppression based on their mechanism and results from previous studies. In present study, it was showed that improvement in renal function was superior in patients who were treated with SRL. In ADHERE study, data analysis showed mean GFR at week 52 post-transplantation was significantly higher in patients who received SRL only in patients with donor with the of 50 years or less 
[26]. This is in line with results from previous study that reported better graft function when combination of TAC and SRL is used as an immunosuppressive regimen in kidney transplant recipient without preexisting interstitial fibrosis and tubular atrophy [27]. In contrast to our study, most studies did not administer SRL exactly in first day after transplantation. most of the studies, administrated SRL three months post-transplantation or ultimately, two or three weeks after transplantation. Concomitant use of SRL with MMF is the preferred immunosuppression regimen in studies on SRL but our approach was to combine SRL with Tacrolimus as an immunosuppression regimen. In our study, immunosuppression induction therapy was done by ATG, but in IL-2 receptor antagonist like Daclizumab or Basiliximab is now being used in patients who are low risk for allograft rejection. In Symphony trial, it was shown that GFR in patients who received TAC and MMF as their immunosuppressive regimen was higher than patients who received SRL with MMF. In the study SRL was administrated from the beginning of immunosuppression in doses similar to our study, but Daclizumab were used for induction therapy and along with SRL, MMF was administered [28]. Mohsen nafar, et al, also were conducted study on 100 kidney transplant patients, CNIs based regimen were compared with SRL based regimen in a for 4 years follow up period. Results were reported that in SRL group, renal function were improved compared to patients who received CNI [29]. Based on the biopsy that were performed for recipients, in control group four patients with ABMR and in test group, acute cellular rejection was reported in two patients. In our study, protocol biopsy was performed (without indication), in control group, and in one patient pathology was compatible with ABMR and in three patients with acute cellular rejection. Patients who received SRL in their immunosuppressant regimen, hasn't showed these two types of rejection. Although there were no significant differences between two groups in triglyceride level, total cholesterol level and serum TG level in SRL included group were higher than control group. There were no significant differences between the two groups regarding infections frequency, NODAT and MAP. In CONCEPT trial, a multi-centered one-year study, the drug regimen was cyclosporine in combination with MMF. In some of these patients, cyclosporine has been changed to SRL after 3 months of transplantation and others continued their immunosuppression by cyclosporine. GFR in patients who received SRL was higher than cyclosporine group. But, episodes of acute rejection in SRL group was more frequent than patients who received cyclosporine. However, most rejections were mild and occurred in time of steroid withdrawal. It seems in CNI-free regimen, induction therapy with Daclizumab due to absence of prolong T-cell depletion is not very strong, Especially, when steroid is withdrawn. In this immunosuppressive drug regimen, induction therapy by ATG due to prolonged T-cell depletion, is a better choice. In some recipients who received $S R L$, adverse drug reactions such as, diarrhea, acne and hypertriglyceridemia were observed, and it led to SRL discontinuation in some cases. There were no differences in the incidence of BK and CMV infections and MAP, total cholesterol and LDL-C level in two groups but TG level in SRL group was higher [30]. In a multi-centered, open-label, randomized controlled, non-inferiority trial, which followed the goal of comparison the effect of SRL plus Extended Release Tacrolimus (ERTC) by method of non-inferiority and SRL dose and through level same as our study, it was proven that immunosuppressive regimen consists of SRL and ERTC was no inferior to combination of MMF and ERTC. Renal function was assessed by serum creatinine level and estimated glomerular filtration rate which were determined by MDRD equation as we did [31]. Although, in our study the incidence of CMV and BKV disease between two groups were not statistically different, in previous 
studies some points were reported. Anti-proliferative effect of SRL besides antiviral effect against CMV and BKV and anticancer effect of SRL are some advantages in using this medication as an immunosuppressive medication [32-35]. In an observational study which continued an open-label, randomized, comparative trial (SPIESSER study), patients followed for 5 years. The original study was to assess the efficacy of SRL/MMF regimen compared to a cyclosporine/MMF in deceased donor kidney transplant recipients. Patients in SRL group had significantly better renal function. Episodes of acute rejection were not statistically different in two groups. Induction therapy in this study made by ATG which was like our study. There were not significant differences regarding total cholesterol, TG level and NODAT[36]. One of the objectives to use SRL in combination with CNIs is to reduce the dose of CNI in order to have less renal function decrease because of CNI's nephrotoxicity. In eight years follow up of heart transplanted patient which use SRL and low-dose tacrolimus as immunosuppressive regimen, it was showed that this approach did not result in superior long-term renal function in when was weight against Full-dose tacrolimus and MMF as immunosuppressive medications[37]. Some limitation to this study were observed and findings of the study should be interpreted with caution. First, this study was done in single-centered approach. Second, Low sample size is considered as the biggest limitation and finally, Insufficient time for follow up is considered as another limitation to this study.

\section{Conclusions:}

our study indicated that combination use of SRL plus TAC increase renal function in kidney transplant recipients in comparison to Mycophenolate plus TAC without more side effect. Based on the data we received from this study it could be suggested that consumption of SRL as an immunosuppressive agent in patient who received kidney transplant could lead to better renal function and increased in GFR. As we said before SRL need more studies with larger number of populations to detect all the limitation and advantage of de novo use of this agent with an CNI. Findings of this study is a clue for further studies to determine long-term outcome of SRL use on transplanted kidney function when we use it in De novo approach.

\section{Abbreviations}

Antibody-Mediated Rejection (ABMR), Antithymocyte Globulin (ATG), Acute Tubular Necrosis (ATN), Body Mass Index (BMI), Cytomegalovirus (CMV), Calcineurin Inhibitors (CNI), Delayed Graft Function (DGF), Extended Release Tacrolimus (ERCT), End Stage Renal Disease (ESRD), Fasting Plasma Glucose (FPG), Glomerular Filtration Rate (GFR), Human Leukocyte Antigen (HLA), Mean Arterial Pressure (MAP) Modification of Diet in Renal Disease Study (MDRD), Membranous glomerulonephritis (MGN), Mycophenolate Mofetil (MMF), New Onset Diabetes After Transplantation (NODAT), Slow Graft Function (SGF), Sirolimus (SRL), Tacrolimus (TAC).

\section{Declarations}


Study was done in accordance with the declaration of Helsinki. It was approved by the ethics committee of Shahid Labbafinejad medical center, Tehran, Iran. Written informed consents were obtained from all patients before enrollment

\section{Consent for publication}

Not applicable

\section{Availability of data and materials}

Data and material would be available only by the approval of corresponding author.

Competing Interests

The authors report no conflicts of interest in this work.

\section{Funding:}

This research was financially supported by Urology and Nephrology Research Center(unrc), Shahid Beheshti University of Medical Sciences, Tehran, Iran.

\section{Authors Contributions}

$\mathrm{FH}$, Study concept and design, Acquisition of data, Drafting of the manuscript, Statistical analysis ; ND, Acquisition of data, Administrative, technical, and material support, Critical revision of the manuscript for important intellectual content ;PA, Acquisition of data, Study concept and design, Critical revision of the manuscript for important intellectual content, Study supervision ;OM, Drafting of the manuscript, Statistical analysis, Critical revision of the manuscript for important intellectual content ;FP, Acquisition of data, Administrative, technical, and material support, Critical revision of the manuscript for important intellectual content ;SS, Acquisition of data, Administrative, technical, and material support, Critical revision of the manuscript for important intellectual content ;FS, Acquisition of data, Administrative, technical, and material support ;MN, Acquisition of data, Study concept and design, Study supervision, Critical revision of the manuscript for important intellectual content ;AF, Acquisition of data, Administrative, technical, and material support ;SZ, Study concept and design, Drafting of the manuscript, Statistical analysis, Critical revision of the manuscript for important intellectual content, Administrative, technical, and material support

\section{Acknowledgment}

We have to express our appreciation to the Phizer pharmaceutical company for its cooperation and worthy help in the provision of medicine during the course of this research.

All Authors read and approved the manuscript

Supporting data could be accessed by contacting correspondence. 


\section{References}

1. Matas A, Smith J, Skeans M, Thompson B, Gustafson S, Schnitzler M, et al.. Am J Transplant. 2014;1:11-44. https://doi.org/10.1111/ajt.12579.

2. Cecka JM. The UNOS Renal Transplant Registry. Clin Transp. 2002;:1:1-20.

3. Meier-Kriesche H, Schold J, Srinivas T, Kaplan B. Lack of improvement in renal allograft survival despite a marked decrease in acute rejection rates over the most recent era. Am J Transplant. 2004;4 (3):378-383. https://doi.org/10.1111/j.1600-6143.2004.00332.x.

4. Bennett W, DeMattos A, Meyer M, Andoh T, Barry J. Chronic cyclosporine nephropathy: the Achilles' heel of immunosuppressive therapy. Kidney international. 1996;50(4):1089-1100. https://doi.org/10.1038/ki.1996.415.

5. Goldstein D, Zuech N, Sehgal V, Weinberg A, Drusin R, Cohen D. Cyclosporine-associated End-stage Nephropathy After Cardiac Transplantation: Incidence and Progression1. Transplantation. 1997;63 (5):664-668. https://doi.org/10.1097/00007890-199703150-00009.

6. Myers B, Sibley R, Newton L, Tomlanovich S, Boshkos C, Stinson E, et al. The long-term course of cyclosporine-associated chronic nephropathy. Kidney Int 1988;33(2):590-600. https://doi.org/10.1038/ki.1988.38.

7. Nankivell B, Borrows R, Fung C, O'connell P, Allen R, Chapman J. The natural history of chronic allograft nephropathy. N Engl J Med. 2003;349(24):2326-2333. https://doi.org/10.1056/NEJMoa020009.

8. Mihatsch M, Kyo M, Morozumi K, Yamaguchi Y, Nickeleit V, Ryffel B. The side-effects of ciclosporineA and tacrolimus. Clin Nephrol. 1998;49(6):356-363.

9. Abramowicz D, Manas D, Lao M, Vanrenterghem Y, Del Castillo D, Wijngaard P, et al. Cyclosporine withdrawal from a mycophenolate mofetil-containing immunosuppressive regimen in stable kidney transplant recipients: a randomized, controlled study. Transplantation. 2002;74(12):1725-1734. https://doi.org/10.1097/01.tp.0000038729.43731.f6.

10. Mourad G, Vela C, Ribstein J, Mimran A. Long-term improvement in renal function after cyclosporine reduction in renal transplant recipients with histologically proven chronic cyclosporine nephropathy. Transplantation. 1998;65(5):661-667. https://doi.org/ 10.1097/00007890-199803150-00010.

11. Ojo A, Hanson J, Wolfe R, Leichtman A, Agodoa L, Port F. Long-term survival in renal transplant recipients with graft function. Kidney Int. 2000;57(1):307-313. https://doi.org/10.1046/j.15231755.2000.00816.x

12. Weir M, Blahut S, Drachenburg C, Young C, Papademitriou J, Klassen D, et al. Late calcineurin inhibitor withdrawal as a strategy to prevent graft loss in patients with suboptimal kidney transplant function. Am J Nephrol. 2004;24(4):379-386. https://doi.org/10.1159/000079390 
13. Campistol J, Eris J, Oberbauer R, Friend P, Hutchison B, Morales J, et al. Sirolimus therapy after early cyclosporine withdrawal reduces the risk for cancer in adult renal transplantation. Clin $\mathrm{J}$ Am Soc Nephrol 2006;17(2):581-589. https://doi.org/10.1681/ASN.2005090993

14. Gonwa T, Hricik D, Brinker K, Grinyo J, Schena F, et al. Improved renal function in sirolimus-treated renal transplant patients after early cyclosporine elimination1. Transplantation 2002;74(11):15601567. https://doi.org/74(11):1560-1567

15. Mota A, Arias M, Taskinen El, Paavonen T, Legendre C, Claesson K, Campistol J, et al. Sirolimusbased Therapy After Early Cyclosporine Withdrawal Results In Significantly Better Renal Histology And Function At 3 Years Following Kidney Transplantation. Am J Transplant 2004;4:953-961. https://doi.org/10.1111/j.1600-6143.2004.00446.x

16. Oberbauer R, Hutchison B, Eris J, Riad H, Claesson K, Lawen J, et al. Three-year assessment of health-related quality of life in sirolimus-treated kidney transplant patients after cyclosporine elimination. Am J Transplant. 2003;20(10):875-83. https://doi.org/10.1111/j.14322277.2007.00547.x

17. Oberbauer R, Segoloni G, Campistol J, Kreis H, Mota A, Lawen J, et al. Early cyclosporine withdrawal from a sirolimus-based regimen results in better renal allograft survival and renal function at 48 months after transplantation. Transpl Int. 2005;18(1):22-28 https://doi.org/10.1111/j.14322277.2004.00052.x

18. Van Hooff J, Squifflet J, Wlodarczyk Z, Vanrenterghem Y, Paczek L. A prospective randomized multicenter study of tacrolimus in combination with sirolimus in renal-transplant recipients. Transplantation. 2003;75(12):1934-1939 https://doi.org/10.1097/01.TP.0000071301.86299.75

19. Vitko S, Wlodarczyk Z, Kyllönen L, Czajkowski Z, Margreiter R, Backman L, et al. Tacrolimus combined with two different dosages of sirolimus in kidney transplantation: results of a multicenter study. Am J Transplant. 2006;6(3):531-538. https://doi.org/10.1111/j.1600-6143.2005.01193.x

20. Ekberg H, Tedesco-Silva H, Demirbas A, Vítko Š, Nashan B, Gürkan A, et al. Reduced exposure to calcineurin inhibitors in renal transplantation. N Engl J Med. 2007;357(25):2562-2575. https://doi.org/10.1056/NEJMoa067411

21. Flechner S, Glyda M, Cockfield S, Grinyó J, Legendre C, Russ G, et al. The ORION study: comparison of two sirolimus-based regimens versus tacrolimus and mycophenolate mofetil in renal allograft recipients. Am J Transplant. 2011;11(8):1633-1644. https://doi.org/10.1111/j.16006143.2011.03573.x

22. Flechner S, Gurkan A, Hartmann A, Legendre C, Russ G, Campistol J, et al. A randomized, open-label study of sirolimus versus cyclosporine in primary de novo renal allograft recipients. Transplantation. 2013;95(10):1233-1241. https://doi.org/ 10.1097/TP.0b013e318291a269

23. Joo D, Yang C, Jeong H, Lim B, Huh K, Chung B, et al. Sirolimus Conversion Efficacy for Graft Function Improvement and Histopathology in Renal Recipients with Mild to Moderate Renal Insufficiency. J Korean Med Sci. 2014;29(8):1069-1076. https://doi.org/ 10.3346/jkms.2014.29.8.1069 
24. Stallone G, Infante B, Grandaliano G, Gesualdo L. Management of side effects of sirolimus therapy. Transplantation. 2009;87(8S):S23-S26. https://doi.org/ 10.1097/TP.0b013e3181a05b7a

25. Levey AS, Bosch JP, Lewis JB, Greene T, Rogers N, Roth D. A more accurate method to estimate glomerular filtration rate from serum creatinine: a new prediction equation. Ann Intern Med. 1999;130(6):461-470. https://doi.org/10.7326/0003-4819-130-6-199903160-00002

26. Rummo O, Carmellini M, Rostaing L, Oberbauer R, Christiaans $M$, Mousson $C$, et al. ADHERE: randomized controlled trial comparing renal function in de novo kidney transplant recipients receiving prolonged-release tacrolimus plus mycophenolate mofetil or sirolimus. Transpl Int. 2017;30(1):83-95. https://doi.org/10.1111/tri.12878

27. Gelens M, Steegh F, van Hooff J, Van Suylen R, Nieman F, van Heurn L, et al. Immunosuppressive regimen and interstitial fibrosis and tubules atrophy at 12 months postrenal transplant. Clin $\mathrm{J} \mathrm{Am}$ Soc Nephrol. 2012;7(6):1010-1017. https://doi.org/ 10.2215/CJN.09030911

28. Ekberg H, Bernasconi C, Tedesco-Silva H, Vitko S, Hugo C, Demirbas A, et al. Calcineurin inhibitor minimization in the Symphony study: observational results 3 years after transplantation. Am J Transplant. 2009;9 (8):1876-1885. https://doi.org/ 10.1111/j.1600-6143.2009.02726.x

29. Nafar M, Alipour B, Ahmadpoor P, Pour-Reza-Gholi F, Samadian F, Samavat S, et al. Sirolimus versus calcineurin inhibitor-based immunosuppressive therapy in kidney transplantation: a 4-year follow-up. Iran J Kidney Dis. 2012;6(4):300

30. Lebranchu Y, Thierry A, Toupance O, Westeel P, Etienne I, Thervet E, et al. Efficacy on renal function of early conversion from cyclosporine to sirolimus 3 months after renal transplantation: concept study. Am J Transplant. 2009;9(5):1115-1123. https://doi.org/10.1111/j.1600-6143.2009.02615.x

31. Huh K, Lee J, Ha J, Oh C, Ju M, Kim C, et al. De novo low-dose sirolimus versus mycophenolate mofetil in combination with extended-release tacrolimus in kidney transplant recipients: a multicentre, open-label, randomized, controlled, non-inferiority trial. Nephrol Dial Transplant. 2017;32(8):1415-1424. https://doi.org/10.1093/ndt/gfx093

32. Webster A, Lee V, Chapman J, Craig J. Target of rapamycin inhibitors (sirolimus and everolimus) for primary immunosuppression of kidney transplant recipients: a systematic review and meta-analysis of randomized trials. Transplantation. 2006;81(9):1234-1248.

htpps://doi.org/10.1097/01.tp.0000219703.39149.85

33. Opelz G, Unterrainer C, Süsal C, Döhler B. Immunosuppression with mammalian target of rapamycin inhibitor and incidence of post-transplant cancer in kidney transplant recipients. Nephrol Dial Transplant 2016;31(8):1360-1367. https://doi.org/10.1093/ndt/gfw088

34. Nashan B, Gaston R, Emery V, Säemann M, Mueller N, Couzi L, et al. Review of cytomegalovirus infection findings with mammalian target of rapamycin inhibitor-based immunosuppressive therapy in de novo renal transplant recipients. Transplantation. 2012;93(11):1075-1085. https://doi.org/ 10.1097/TP.0b013e31824810e6

35. Jouve T, Rostaing L, Malvezzi P. Place of mTOR inhibitors in management of BKV infection after kidney transplantation. J nephropathol. 2016;5(1):1. https://doi.org/10.15171/jnp.2016.01

Page $11 / 16$ 
36. Lebranchu Y, Snanoudj R, Toupance O, Weestel P, De Ligny B, Buchler M, et al. Five-year results of a randomized trial comparing de novo sirolimus and cyclosporine in renal transplantation: the spiesser study. Am J Transplant. 2012;12(7):1801-1810. https://doi.org/ 10.1111/j.1600-6143.2012.04036.x

37. Guethoff S, Stroeh K, Grinninger C, Koenig M, Kleinert E, Rieger A, et al. De novo sirolimus with lowdose tacrolimus versus full-dose tacrolimus with mycophenolate mofetil after heart transplantation-8-year results. Heart Lung Transplant. 201534(5):634-642.

https://doi.org/10.1016/j.healun.2014.11.025

\section{Tables}

Baseline Demographic and Clinical Data in Kidney Transplant Recipients Receiving SRL-based and Mycophenolate-based Immunosuppressive Regimen*

\begin{tabular}{|c|c|c|c|c|}
\hline \multicolumn{2}{|l|}{ Variable } & \multirow{2}{*}{$\begin{array}{c}\text { Test group } \\
\text { 15/7 }\end{array}$} & \multirow{2}{*}{$\begin{array}{c}\text { Control group } \\
13 / 5\end{array}$} & \multirow{2}{*}{$\begin{array}{c}p \text {-value } \\
0.528\end{array}$} \\
\hline Sex (ratio) & Male/Female & & & \\
\hline Age (years) & & $33.7 \pm 9.9$ & $35.5 \pm 12.2$ & 0.378 \\
\hline BMI $\left(\mathrm{kg} / \mathrm{m}^{2}\right)$ & & $24.3 \pm 3.7$ & $24.2 \pm 3.6$ & 0.856 \\
\hline \multirow[t]{3}{*}{ Reason for CKD (\%) } & Hypertension & 22.2 & 18.3 & 0.235 \\
\hline & Diabetes mellitus & 11.2 & 4.5 & \\
\hline & Others & 66.6 & 77.2 & \\
\hline \multirow[t]{2}{*}{ Source of Allograft Tissue (\%) } & Living, unrelated & 66.7 & 45.5 & 0.153 \\
\hline & Cadaver & 33.3 & 54.5 & \\
\hline
\end{tabular}


*Values are means unless otherwise explained.

Mean Clinical and Laboratory Values in Kidney Transplant Recipients Receiving SRL-based and Mycophenolate-included .Immunosuppressive Regimen after 6 months of Follow-up

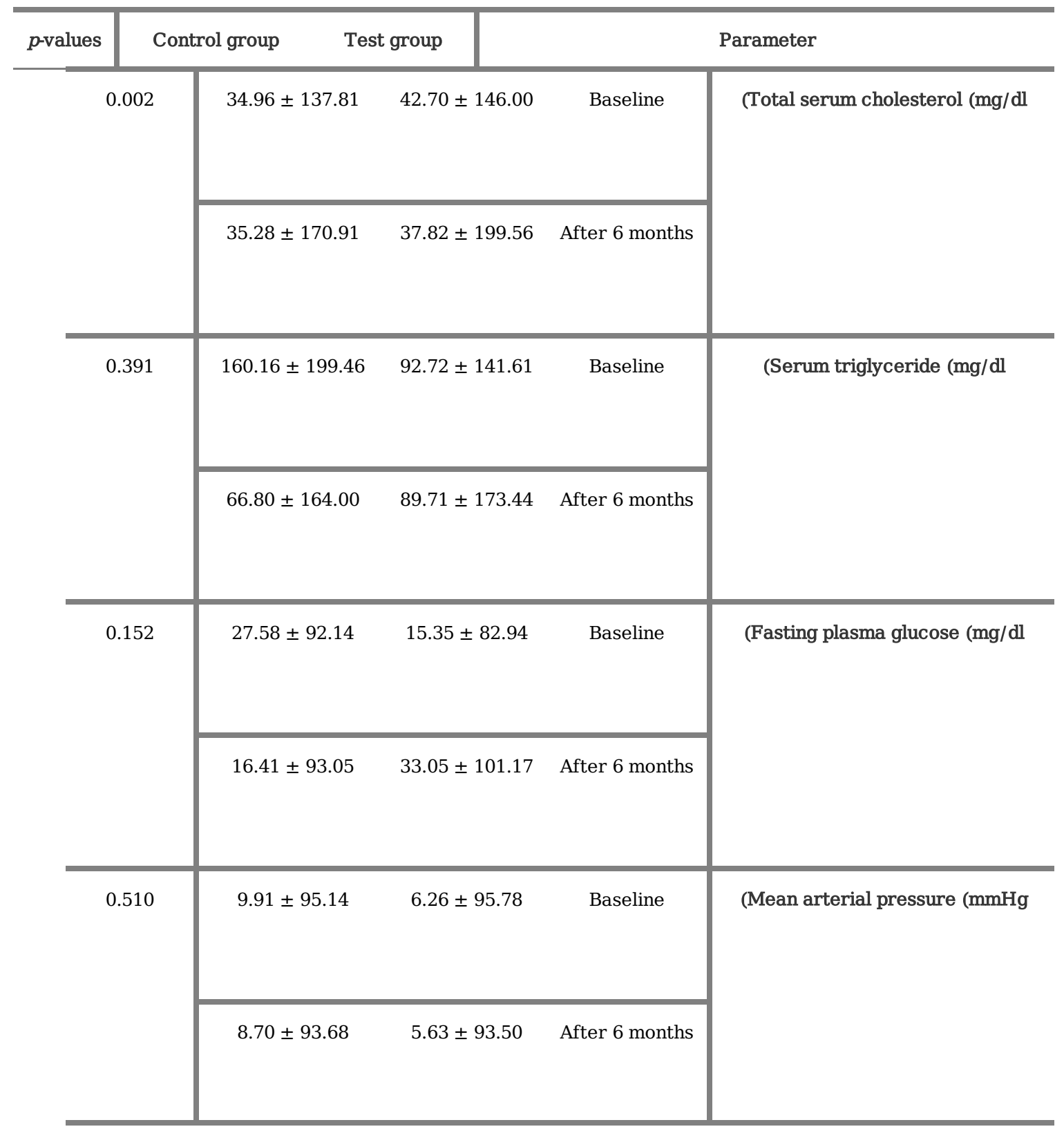


Mean Length of Stay (LOS) and re-hospitalization in Kidney Transplant Recipients Receiving SRL-based and Mycophenolate-based Immunosuppressive Regimen

\begin{tabular}{cccc}
\hline -valuep & Control group & Test group & Parameter \\
\hline 0.329 & $13.54 \pm 5.59$ & $11.44 \pm 2.95$ & LOS (days) \\
\hline 0.616 & $0.50 \pm 0.86$ & $0.44 \pm 0.70$ & Mean number of admission (n) \\
\hline
\end{tabular}

\section{Figures}

I

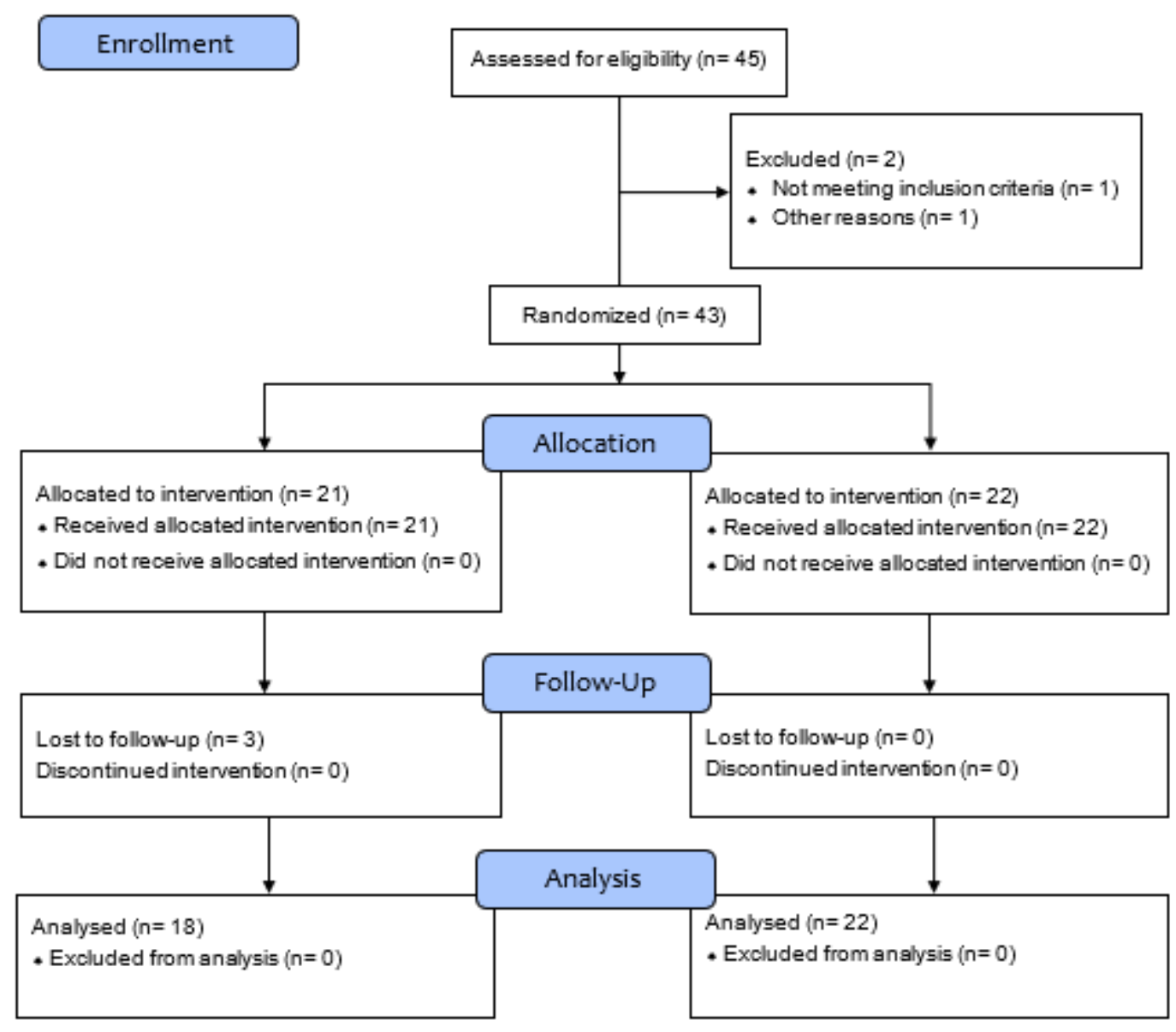


Figure 1

Study flow diagram. The diagram illustrates the study enrollment and disposition of trial participants

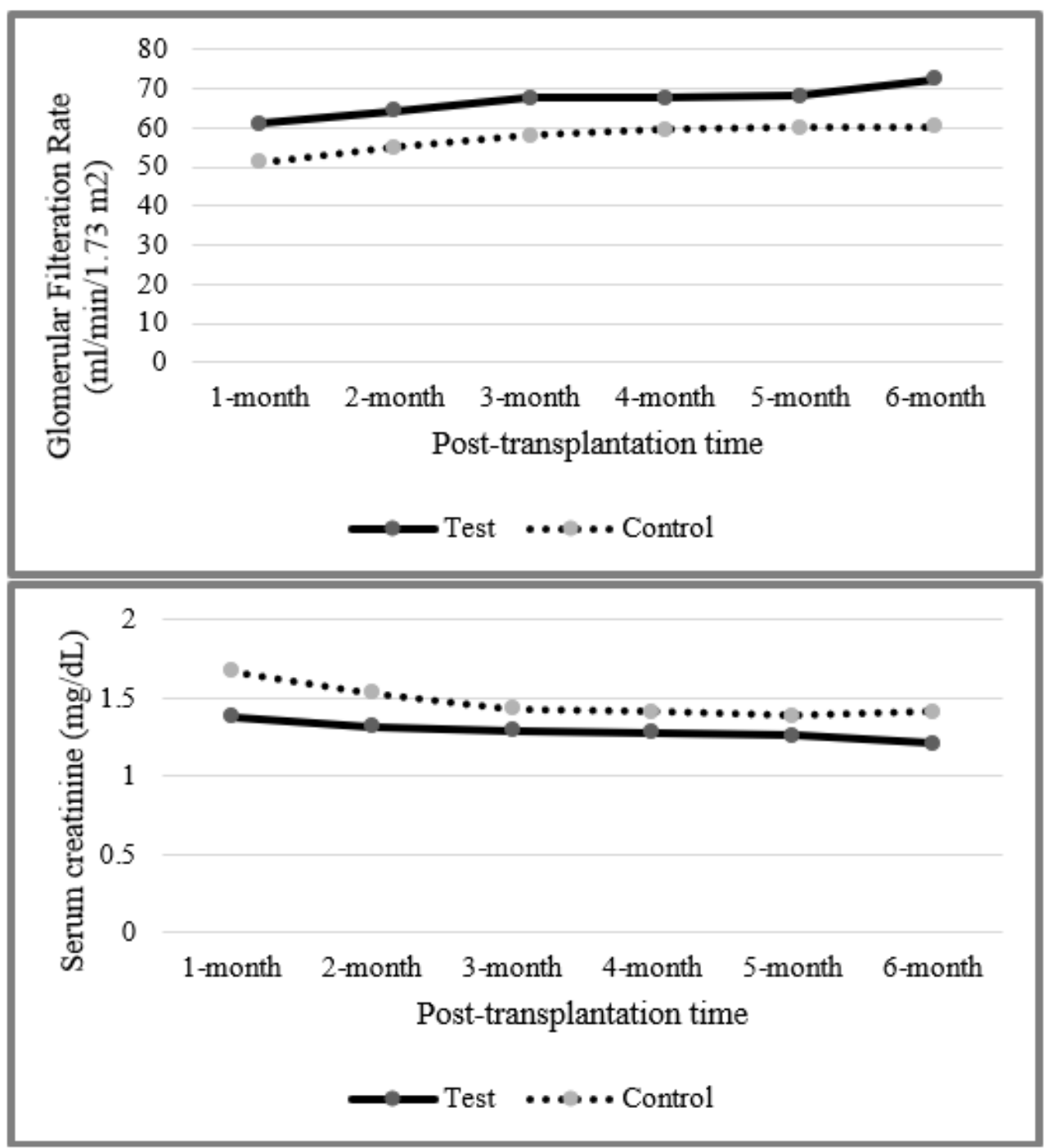

Figure 2

Serum creatinine level and eGFR during the 6 months post-transplantation follow-up in patients receiving SRL-included and Mycophenolate-included immunosuppressive medication regimen. 


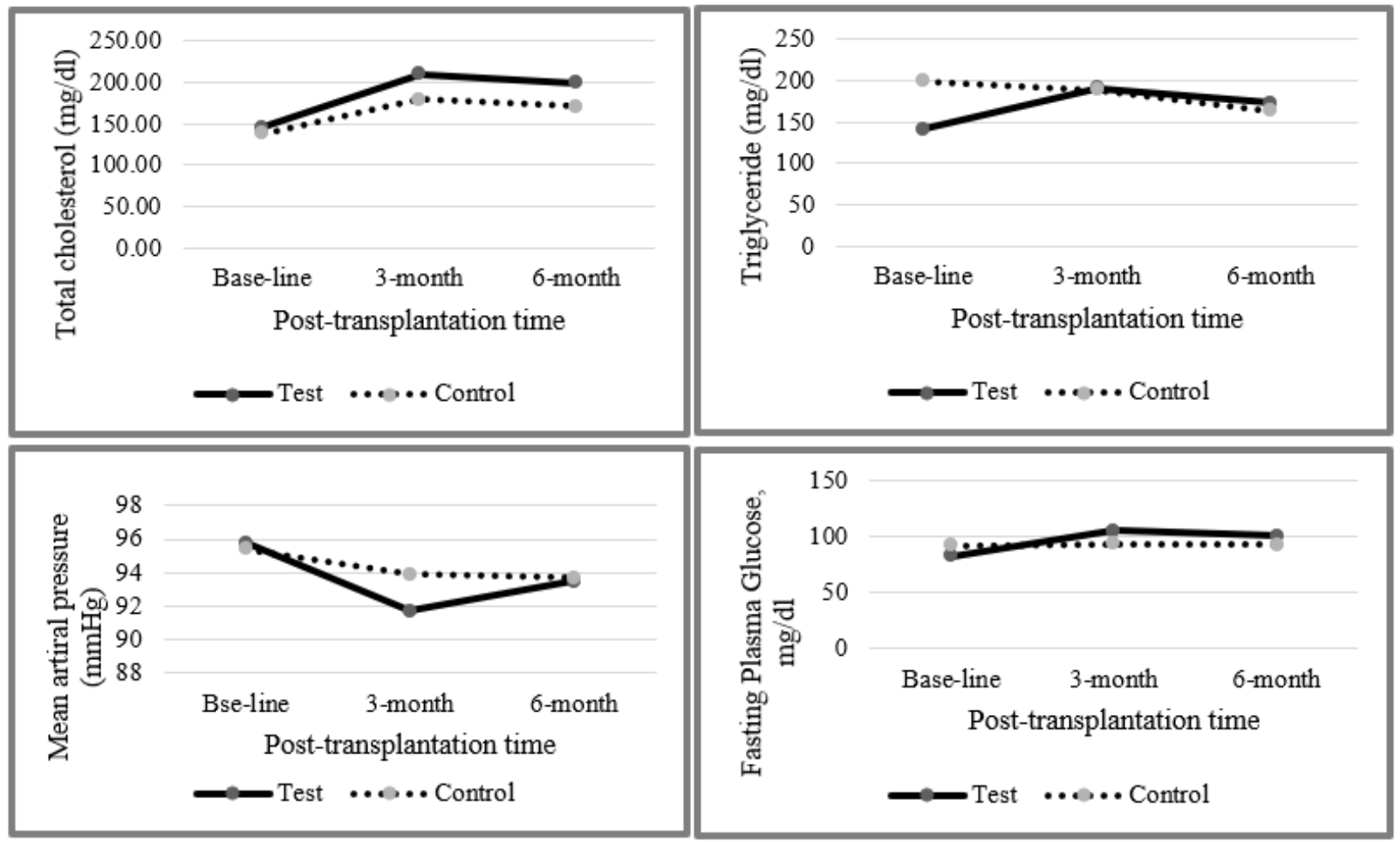

Figure 3

Serum total cholesterol level, Serum triglyceride level, MAP, FPG during the 6 months post-transplantation follow-up in patients receiving SRL-included and Mycophenolate-included immunosuppressive medication regimen.

\section{Supplementary Files}

This is a list of supplementary files associated with this preprint. Click to download.

- CONSORT2010Checklist.doc 